\title{
Outcomes of covered versus bare balloon expandable versus self-expanding stents for the kissing stent treatment of aortoiliac bifurcation
}

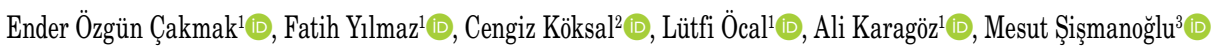 \\ ${ }^{1}$ Department of Cardiology, University of Medical Sciences, Kartal Koşuyolu High Specialty Training and Research Hospital, Istanbul, Turkey \\ ${ }^{2}$ Department of Cardiology, Bezmialem Vakrf University, Faculty of Medicine, Istanbul, Turkey \\ ${ }^{3}$ Department of Cardiovascular Surgery, University of Medical Sciences, Kartal Koşuyolu High Specialty Training and Research Hospital, Istanbul, Turkey
}

\begin{abstract}
Objectives: This study aims to compare the outcomes of self-expanding stents (SESs), bare balloon expandable stents (BESs), and covered stents $(\mathrm{CSs})$ in the kissing stent (KS) treatment of aortoiliac bifurcation (AIB) lesions and to identify the predictors of in-stent restenosis (ISR) development.

Patients and methods: Between January 2012 and December 2018, a total of 123 patients (108 males, 15 females; mean age: $62.4 \pm 9.1$ years; range, 37 to 85 years) who had primary KS reconstruction of AIB for symptomatic aortoiliac occlusive disease (AIOD) were retrospectively analyzed. There were 31 patients in the SES group, 56 patients in the BES group, and 36 patients in the CS group. Technical and clinical success, intra- and perioperative complications, determinants of ISR and patency rates were documented.

Results: Technical success was achieved in $99.2 \%$ of the patients. Clinical symptom improvement was achieved in all three groups (ABI, $\mathrm{p}=0.45$; Rutherford, $\mathrm{p}=0.35$ ). Median follow-up was 35 (range, 22.5 to 50) months. Primary patency at one and five years were $100 \%$ and $82 \%$, respectively for SES, $98 \%$ and $88 \%$, for BES, and $92 \%$ and $85 \%$ for CS ( $\mathrm{p}=0.53$ ). Regression analysis revealed a longer aortic stent length (hazard ratio [HR]: 5.94, 95\% confidence interval [CI]: 1.34-26.25, $\mathrm{p}=0.035$ ) to be significant determinants of ISR. The receiver operating characteristic curve identified $15-\mathrm{mm}$ as the cut-off value with an area under the curve of 0.644 . Primary patency rates for $<15-\mathrm{mm}$ aortic stent length were $100 \%$ and $88 \%$ at 12 and 60 months, respectively ( $\mathrm{p}=0.028)$.

Conclusion: The use of SES, BES, and CS for KS treatment of AIB offers favorable and compatible long-term patency with aortic stent length being an independent factor affecting ISR.
\end{abstract}

Keywords: Aortic stent length, aortoiliac bifurcation, kissing stents, patency, restenosis.

The aortoiliac bifurcation (AIB) is a predominant location of atherosclerosis, and stenosis in this area may lead to disabling claudication or chronic limb-threatening ischemia. It can be treated surgically, endovascularly, or in a hybrid manner. Open surgery, which has been considered the gold-standard treatment for years, is related to an outstanding long-term patency rates up to $90 \% .^{[1,2]}$ However, it has been also associated with an early mortality rate of $3.3 \%$ and a significant early complication rate of $8.3 \%$, including bleeding and cardiac failure. ${ }^{[3,4]}$ With the rapid development of endovascular devices and experience of interventionists in recent years, there has been a paradigm shift toward endovascular-first strategy for most stenotic and occlusive lesions of the iliac artery. Additionally, spontaneous iliac artery dissections can be treated safely with the development of endovascular methods. ${ }^{[5]}$

Kissing stent (KS) treatment (simultaneously deployed stents) has become a well-accepted intervention for AIB lesions owing to its minimally invasive nature and feasibility in high-risk surgery

Received: March 03, 2021 Accepted: March 15, 2021 Published online: April 16, 2021

Correspondence: Ender Özgün Çakmak, MD. Kartal Koșuyolu Yüksek İhtisas Eüitim ve Araștırma Hastanesi Kardiyoloji Kliniŏi, 34865 Kartal, İstanbul, Türkiye. e-mail: enderozguncakmak@gmail.com 
patients. The KS treatment is effective as a primary therapy for AIB stenosis and occlusions having one-year primary and secondary patency rates ranging from 70 to $97 \%$ and from 88 to $100 \%$, respectively. ${ }^{[6]}$ The long-term five-year patency rates outcome has not matched that of open surgery due to a high rate of reinterventions. ${ }^{[7]}$ However, this technique has several established benefits over open surgery, including shorter length of hospital stay, less early complications, and lower 30-day mortality rate up to 0.7 vs. $2.6 \%{ }^{[8]}$

Currently, self-expanding stents (SESs), bare balloon expandable stents (BESs), and covered stents (CSs) are used for AIB lesions; however, there is no established consensus on which type of stent should be deployed. Of note, whether all three types of stents are comparably safe, suitable, and effective for AIB disease is debatable. All three stent types can be used for KS treatment; however, previous studies, as also documented in a recently meta-analysis data, ${ }^{[7]}$ compared only two stent types for outcomes. In the present study, we aimed to compare the short- and long-term outcomes of the SESs, BESs, and CSs for the treatment of AIB lesions.

\section{PATIENTS AND METHODS}

This single-center, retrospective study was conducted at University of Medical Sciences, Kartal Koşuyolu High Specialty Training and Research Hospital, Department of Cardiology, between January 2012 and December 2018. A systematic review was conducted to identify all consecutive patients treated for aortoiliac occlusive disease (AIOD) using prospective hospital database. The search identified a total of 1,211 patients who underwent 1,653 procedures with target lesions in the common iliac artery (CIA), and/or external iliac artery (EIA). A total of $194 \mathrm{KS}$ for AIB were determined. Previous endovascularly treated or surgically operated AIB lesions, infrarenal aortic occlusions (Leriche syndrome), and aortic type stents deployed cases and follow-up period less than 12 months were excluded. Finally, a total of 123 patients (108 males, 15 females; mean age: $62.4 \pm 9.1$ years; range, 37 to 85 years) who had primary KS reconstruction of AIB for symptomatic AIOD were included in present study. All patients were informed about the diagnostic and therapeutic procedures and a written informed consent was obtained. The study protocol was approved by the Kartal Koşuyolu High Specialty Training and Research Hospital Clinical Investigations Ethics Commettee (date/no: 25/08/2020/ 2020/6/342). The study was conducted in accordance with the principles of the Declaration of Helsinki.

Baseline characteristics of the patients, clinical status, perioperative, and postoperative data were obtained through the hospital records. All patients were assessed preoperatively by duplex ultrasound (DUS), and/or computed tomography angiography (CTA) of the aorta and lower extremities. Comorbidities or risk factors, such as coronary artery disease, peripheral artery disease, hypertension, diabetes mellitus, dyslipidemia, and history of smoking use were recorded. All patients had pre-procedural peripheral pulse status, ankle-brachial index (ABI) measurements, and DUS findings. In selected patients, for the anatomical characterization (i.e., arterial network assessment) of AIB and guidance for optimal endovascular treatment strategy, we performed CTA or digital subtraction angiography at the time of coronary angiography.

The categories of aortoiliac lesions were defined on the basis of the Trans-Atlantic Inter-Society Consensus II (TASC-II) classification, and the severity of ischemia were graded on the basis of the Rutherford classification. ${ }^{[9,10]}$ The indication for the KS technique was based on the anatomy of the lesion. It was used in the presence of bilateral common iliac diseases with or without terminal aortic involvement, regardless of the length and type (occlusion or stenosis) of the lesions.

\section{Endovascular technique}

Preferably, a standard arterial access technique was used with bilateral femoral approach. Brachial access was rarely used for to ease the operation in patients with bilateral occlusion of common iliac arteries. Brachial access was used for osteal occlusions of bilateral common iliac arteries $(n=4)$ and after failure of crossing the lesion retrogradely via femoral access $(n=9)$. The diameter of the affected iliac segment and the length of the lesion were bilaterally measured on the initial angiograms for accurate sizing of stents and balloons. If the lumen was too narrow to position the stents, predilatation of the stenosis was performed. The proximal ends of the stents were positioned at or above the aortic bifurcation to cover the entire stenotic segment. The KSs were deployed simultaneously. The choice of stent type was left to the operator's choice; however, in general, BESs or CSs were used preferably for severely calcified, osteal lesions, while SESs were placed for tortuous, long lesions. The Epic $^{\mathrm{TM}}$ self-expanding nitinol stent (Boston Scientific Corp., MA, USA), the Express ${ }^{\mathrm{TM}}$ bare BES (Boston Scientific Corp., MA, USA) and Advanta ${ }^{\mathrm{TM}}$ V12 
balloon expandable CS (Atrium Medical Corp., NH, USA) were the stent models used. Post-dilatation was mainly selective. At the end of the operation, final angiography was applied and technical success was defined as a $<20 \%$ residual stenosis. All patients were discharged one or two days after stenting on acetylsalicylic acid and clopidogrel therapy. Dual antiplatelet treatment continued for at least six months.

\section{Data collection}

Intra- and peri-operative data were collected from operation documents and by reviewing patients' angioplasty interventions on a workstation using the hospital INFINITT (Infinitt Healthcare Inc., NJ, USA) system. The parameters including type of the lesion, aorta characteristics, type, number, and diameter of stents, concomitant endovascular treatment of outflow vessels, and complications were noted. Complications included dissection, rupture, puncture site thrombosis, renal failure, distal embolism, hematomas, and pseudoaneurysms. Aortic stent length, as the distance from proximal end of KSs to aortic carina, was calculated from the hospitals INFINITT system for each patient.

The follow-up visits were scheduled at four weeks, six and 12 months after stenting. Thereafter, annual visits were performed or whenever symptoms developed. Follow-up program was consisted of clinical examination and DUS scanning with ABI measurement. At least one imaging test (color DUS, CTA or conventional angiography) was performed at one year, or in cases with $>0.15$ decrement in ABI or in a one Rutherford category worsening of symptoms. In-stent restenosis (ISR) was diagnosed, when a significant restenosis was defined as $\geq 50 \%$ stenosis on CTA or conventional angiography, a peak systolic velocity (PSV) ratio of $\geq 2.5$ between the area of maximum lumen reduction and the pre-stenosis area, uniform PSV of $<50 \mathrm{~cm} / \mathrm{s}$ throughout the stent on DUS or requirement for target vessel revascularization. Reintervention was carried out in patients with recurrent clinically relevant symptoms and significant ISR. Late results were analyzed including the ISR, reinterventions, and all-cause mortality. ${ }^{[10]}$ Primary patency was referred as uninterrupted patency without any reintervention at the margin of the treated segment, secondary patency was referred as restored patency after reintervention at the original treated segment. Additionally, amputation and all-cause mortality were noted. The patients were divided into three groups based on the type of KS deployed as the SES (Group 1, n=31), BES (Group 2, n=56), and CS (Group 3, n=36) group.

\section{Statistical analysis}

Statistical analysis was performed using the "rms", "Hmisc" and "ggplot" survival, survminer packages with the $\mathrm{R}$ version 4.0 software (R Project, Vienna, Austria). Continuous variables were expressed in mean \pm standard deviation (SD) or median (interquartile range [IQR]: $25^{\text {th }}-75^{\text {th }}$ ), while categorical variables were expressed in number and frequency. Clinical variables

Table 1. Baseline demographic and clinical characteristics of patients

\begin{tabular}{|c|c|c|c|c|c|c|c|c|c|c|}
\hline & \multicolumn{3}{|c|}{$\operatorname{SES}(\mathrm{n}=31)$} & \multicolumn{3}{|c|}{$\operatorname{BES}(n=56)$} & \multicolumn{3}{|c|}{$\mathrm{CS}(\mathrm{n}=36)$} & \multirow[b]{2}{*}{$p$} \\
\hline & $\mathrm{n}$ & $\%$ & Mean $\pm S D$ & $\mathrm{n}$ & $\%$ & $\mathrm{Mean} \pm \mathrm{SD}$ & $\mathrm{n}$ & $\%$ & Mean \pm SD & \\
\hline Age (year) & & & $65.2 \pm 8.8$ & & & $61.6 \pm 9.5$ & & & $61.5 \pm 9.1$ & 0.15 \\
\hline \multicolumn{11}{|l|}{ Sex } \\
\hline Male & 27 & 87.1 & & 46 & 82.1 & & 35 & 97.2 & & 0.09 \\
\hline Diabetes mellitus & 13 & 41.9 & & 21 & 37.5 & & 6 & 16.7 & & 0.06 \\
\hline Hypertension & 26 & 83.9 & & 44 & 78.6 & & 31 & 86.1 & & 0.62 \\
\hline Dyslipidemia & 23 & 74.1 & & 47 & 83.9 & & 23 & 63.9 & & 0.09 \\
\hline Chronic kidney disease & 2 & 6.5 & & 6 & 10.8 & & 3 & 8.3 & & 0.34 \\
\hline Smoking & 25 & 80.6 & & 45 & 80.4 & & 30 & 83.3 & & 0.93 \\
\hline Peripheral artery disease & 9 & 29 & & 17 & 30.4 & & 9 & 25 & & 0.51 \\
\hline Coronary artery disease & 15 & 48.4 & & 23 & 41.1 & & 10 & 27.8 & & 0.21 \\
\hline Congestive heart failure & 13 & 41.9 & & 12 & 21.4 & & 5 & 13.9 & & 0.02 \\
\hline Rutherford & & & & & & & & & & 0.14 \\
\hline 2 & 14 & 45.1 & & 28 & 50 & & 19 & 52.8 & & \\
\hline 3 & 11 & 35.5 & & 23 & 41.1 & & 14 & 38.9 & & \\
\hline 4 & 4 & 12.9 & & 3 & 5.4 & & 3 & 8.3 & & \\
\hline $5 / 6$ & 2 & 6.5 & & 2 & 3.5 & & 0 & 0 & & \\
\hline Pre-procedure ABI & & & $0.5 \pm 0.2$ & & & $0.5 \pm 0.2$ & & & $0.6 \pm 0.2$ & 0.229 \\
\hline
\end{tabular}

SES: Self-expanding stent; BES: Bare balloon expandable stent; CS: covered balloon expandable stent; SD: Standard deviation; ABI: Ankle brachial index. 
were compared using the Student's t-test (normally distributed data), chi-square test, or Fisher's exact test for categorical data, and Mann-Whitney $U$ test for non-normally distributed continuous data and ranked data, as appropriate. Independent predictor variables were chosen according to the results of previous studies and the stepwise backward univariate analysis of the present study. The Cox regression univariate model was performed using the patients' variables, lesion characteristics, vessel characteristics, and stent characteristics. Multivariable Cox regression model was performed using variables that were significant per se and also including age, hypertension, chronic total occlusion, stent type, and aortic stent length. The results of the Cox regression analyses were given as hazard ratios (HRs) with $95 \%$ confidence intervals (CIs). The only independent predictor for ISR was further examined via receiver operating characteristic (ROC) curve to determine the optimal cut-off value by Youden index to discriminate between patients with and without ISR. The primary patency curves and rates were constructed using the Kaplan-Meier method and compared with the log-rank test. A $p$ value of $<0.05$ was considered statistically significant.

\section{RESULTS}

Baseline demographic and clinical characteristics of the patient groups are summarized in Table 1. The indication for KS reconstruction was claudication (Rutherford 2-3) in 109 (88.6\%) patients and critical limb ischemia (Rutherford 4-6) in 14 (11.4\%). Intervention was applied for claudication in $25(80.6 \%)$ patients in the SES group, in 51 (91.1\%) patients in the BES group, and in 33 (91.7\%) patients in the CS group.

The TASC II C and D lesions were 17 (54.8\%), 19 (34.4\%), $20(55.6 \%)$ in SES, BES, and CS groups, respectively. Chronic total occlusion in at least one CIA ostium was detected in $38.7 \%$ of Group 1, 37.5\% in Group 2, and in $63.9 \%$ in Group 3 (group 1 vs. group $2 \mathrm{p}=0.53$, group 1 vs. group $3 \mathrm{p}<0.01$, group 2 vs. group $3 \mathrm{p}<0.01$ ). However, regression analysis showed no independent relationship between chronic total occlusion and KS ISR (univariate analysis, $\mathrm{p}=0.14$; multivariate analysis, $\mathrm{p}=0.21$ ). Table 2 shows the lesion, vessel, and stent characteristics.

The technical success rate was $99.2 \%(\mathrm{n}=1$, false lumen stented then failed to pass through the true lumen). Of 123 consecutive KS procedures, 31 (25.2\%) had SES, 56 (45.5\%) had BES, and 36 (29.3\%) had CS deployment. The EIA was involved during stenting at least one side in 49 (39.8\%) patients. There was no significant difference among the groups in terms of stent diameters at bifurcation, aortic stent length, and total stents implanted. Although the total stent length was different among the groups $(\mathrm{p}<0.001)$, univariate regression analysis indicated no significant relationship between total stent length and KS ISR $(p=0.30)$. Other vessel, lesion, and stent characteristics did not differ significantly among the groups (Table 2 ).

Eighteen complications including in-hospital mortality $(n=2)$ developed. Seven flow-limiting dissections occurred in the iliac arteries and were treated by additional stent deployment. One distal embolism to infrapopliteal segment was treated completely by transient anti-coagulation. Three hematomas and two pseudoaneurysms occurred at the femoral access sites, and hematomas were eliminated by compression. One of the pseudoaneurysms were managed by ultrasound-guided compression and the other one by surgery. Three puncture site thromboses developed at the brachial artery accesses site, and two were managed by injecting low-molecular-weight heparin and one by surgical embolectomy. Within the first $24 \mathrm{~h}$, two acute KS thromboses developed. Urgent percutaneous transluminal angioplasty was performed; however, both balloon dilatations and thrombolytic infusions were failed to recanalize the lumens. These two patients and the patient with the failed intervention were referred to surgery for aortobifemoral (ABF) bypass. Of two cases with in-hospital mortality, one died in the perioperative period after ABF bypass surgery (due to comorbidities of heart and kidney failure), while the other died despite a successful intervention, due to comorbidities and sepsis related to distal lower limb wounds.

The median follow-up was 35 (range, 22.5 to 50) months (data not shown), with the SES group being the longest by 37 (range, 24 to 48.5) months, which was not statistically significant $(p=0.85)$. Twelve (9.8\%) patients died from all-cause mortality. Significant ISR was detected in 14 (11.4\%) patients involving the entire length of the stent in 10 cases. Of 14 ISR cases, six were in the BES group and four each in the SES and CS groups, respectively $(\mathrm{p}=0.95)$. Among 51 (41.5\%) patients whose stents extended $>15 \mathrm{~mm}$ into the aorta, nine (17.6\%) had ISR. All 14 patients underwent endovascular reintervention: in 10 cases, balloon angioplasty was sufficient, two patients had angioplasty with stenting, and two were referred to open surgery (ABF bypass). 


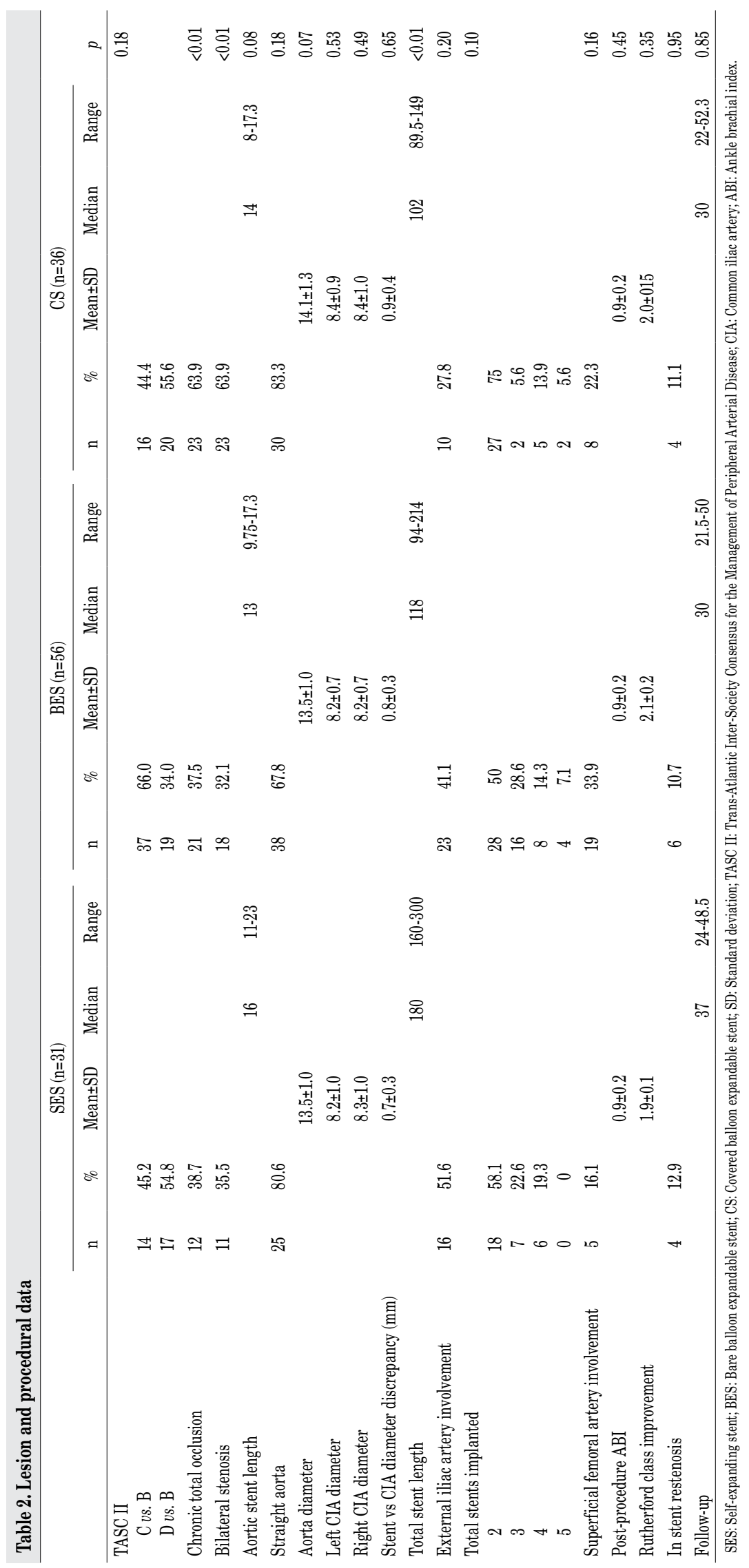




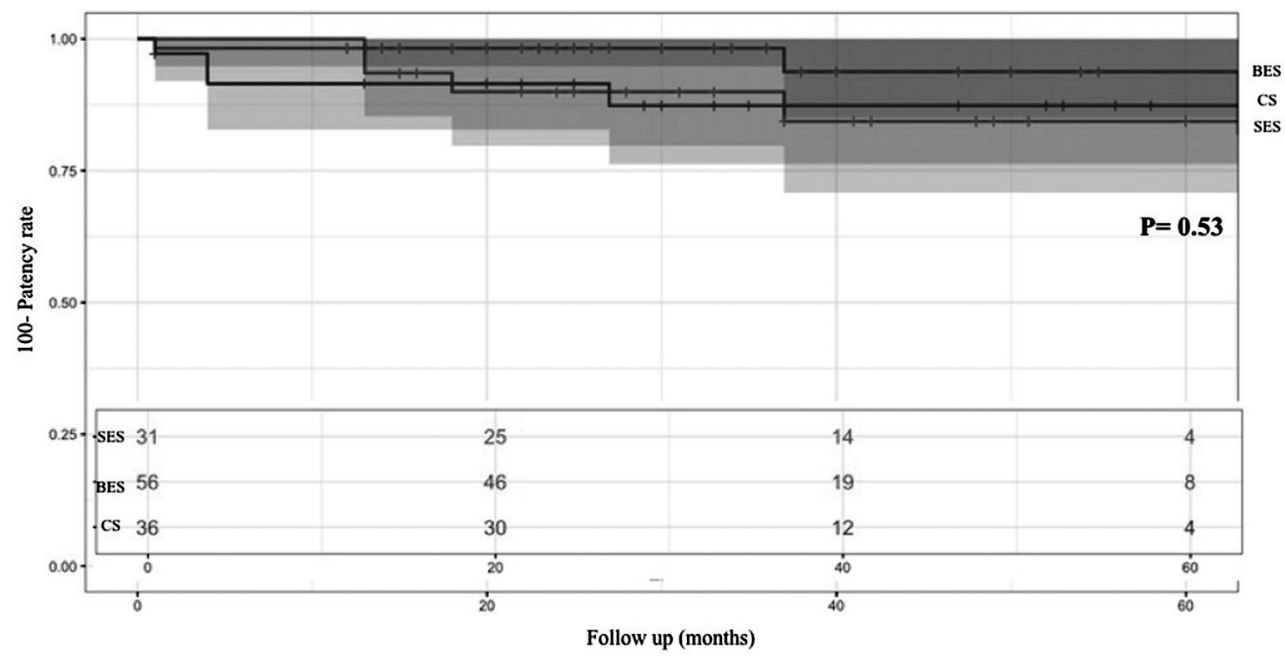

Figure 1. Kaplan-Meier curves of overall primary patency.

BES: Bare balloon expandable stent; CS: Covered balloon expandable stent; SES: Self-expanding stent.

During the follow-up period, 11 (8.9\%) patients underwent distal lower limb artery endovascular therapy for significant lesions. Angioplasty procedures were performed in six superficial femoral artery, one popliteal artery, and four infrapopliteal artery lesions.

The primary patency rates at 12 months were excellent in the SES, BES, and CS groups at 100\%, $98 \%, 92 \%$, respectively. At 60 months, the primary patency rates decreased to $82 \%, 88 \%$, and $85 \%$, respectively ( $p=0.53$ log-rank test). Figure 1 shows the primary patency rates of three stent types.
Stent restenosis occurred in 14 (11.4\%) patients: six were in the BES group and four each in the SES and CS groups, respectively $(p=0.95)$. Univariate Cox regression model (Table 3 ) revealed only TASC II D versus B class (HR: 6.08, 95\% CI: $1.35-27.33, \mathrm{p}=0.01)$ and femoropopliteal tract involvement (HR: 3.70, 95\% CI: 1.18-11.58, $\mathrm{p}=0.02$ ) to be variables favoring ISR development, although two factors failed to maintain significance in the multivariate analysis. Stent type did not show any significant relationship in the univariate analysis and was not an independent risk factor for ISR in

Table 3. Risk factors of restenosis in the kissing stents treatment of aortoiliac bifurcation lesions

\begin{tabular}{|c|c|c|c|c|c|c|}
\hline & \multicolumn{3}{|c|}{ Univariate analysis } & \multicolumn{3}{|c|}{ Multivariate analysis } \\
\hline & $\mathrm{HR}$ & $95 \% \mathrm{CI}$ & $p$ & $\mathrm{HR}$ & $95 \% \mathrm{CI}$ & $p$ \\
\hline Age (57 to 70 years) & 0.79 & $0.35-1.78$ & 0.57 & 0.41 & $0.16-0.99$ & 0.03 \\
\hline \multicolumn{7}{|l|}{ Sex } \\
\hline Male & 0.50 & $0.14-1.97$ & 0.32 & & & \\
\hline Hypertension & 0.43 & $0.11-1.66$ & 0.22 & 1.38 & $0.26-7.21$ & 0.69 \\
\hline Diabetes mellitus & 0.68 & $0.18-2.54$ & 0.57 & & & \\
\hline Coronary artery disease & 1.75 & $0.56-5.47$ & 0.33 & & & \\
\hline Peripheral artery angioplasty history & 1.85 & $0.59-5.80$ & 0.29 & & & \\
\hline \multicolumn{7}{|l|}{ TASC II } \\
\hline C vs. B & 2.02 & $0.33-12.36$ & 0.44 & 1.09 & $0.12-9.31$ & 0.93 \\
\hline D vs. B & 6.08 & $1.35-27.33$ & 0.01 & 4.88 & $0.45-52.34$ & 0.30 \\
\hline Chronic total occlusion & 2.64 & $0.72-9.63$ & 0.14 & 2.87 & $0.53-15.41$ & 0.21 \\
\hline Stent type & 0.86 & $0.17-4.28$ & 0.86 & 1.19 & $0.13-10.53$ & 0.87 \\
\hline Aortic stent length (10 to $19 \mathrm{~mm}$ ) & 2.29 & $0.91-5.78$ & 0.07 & 5.94 & $1.34-26.25$ & 0.02 \\
\hline Total stent length (94 to $224 \mathrm{~mm}$ ) & 1.42 & $0.72-2.79$ & 0.30 & & & \\
\hline External iliac artery involvement & 3.44 & $0.98-12.02$ & 0.06 & & & \\
\hline Femoropopliteal tract involvement & 3.70 & $1.18-11.58$ & 0.02 & 3.72 & $0.75-18.3$ & 0.10 \\
\hline Stent vs CIA diameter discrepancy (mm) & 2.83 & $0.15-1.15$ & 0.27 & & & \\
\hline
\end{tabular}




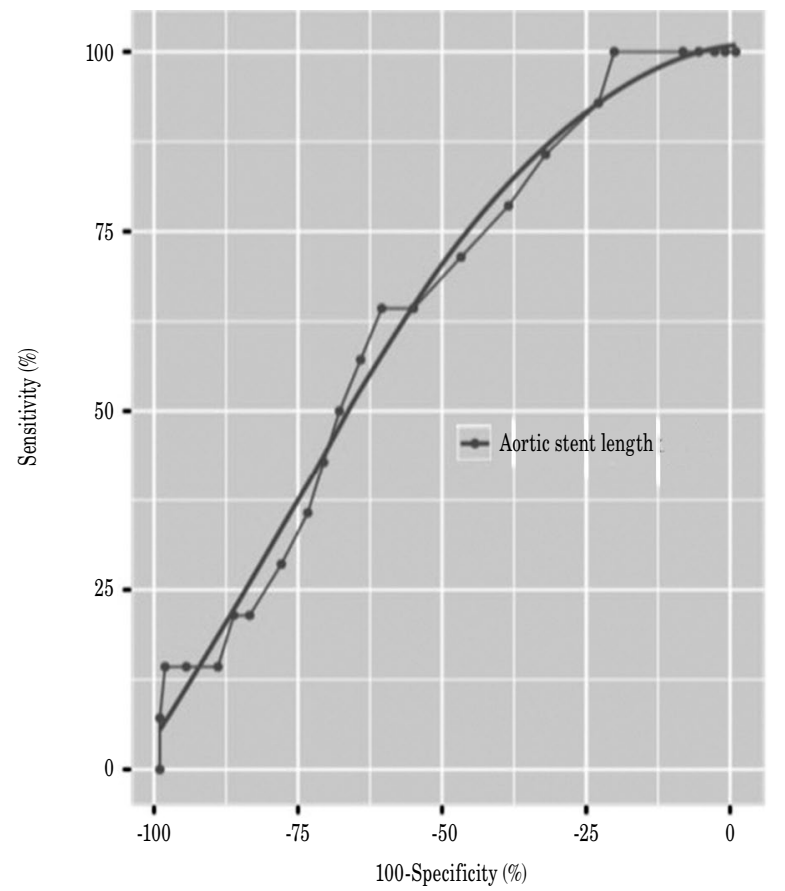

Figure 2. Receiver operator characteristics (ROC) analysis for the length of the aortic stent segment determined a cut-off value for aortic stent length of $15 \mathrm{~mm}$ for predicting in stent restenosis with $64.3 \%$ sensitivity, $61.5 \%$ specificity (AUC 0.644).

AUC: Area under the curve.

the multivariate Cox regression model (Table 3). Multivariate analysis showed a longer aortic stent length (HR: 5.94, 95\% CI: 1.34-26.25, p=0.02) and younger age (HR: 0.41, 95\% CI: 0.16-0.99, $\mathrm{p}=0.03)$ to be significant determinants of ISR. The ROC analysis (Figure 2) identified an optimal cut-off value of $15 \mathrm{~mm}$ based on the Youden index (64.3\% sensitivity, $61.5 \%$ specificity), and area under the curve (AUC) of 0.644. Dichotomization using the $15-\mathrm{mm}$ cut-off value created excellent primary patency rates for patients' aortic stent length of $<15 \mathrm{~mm}(100 \%$ and $88 \%$ at 12 , and 60 months, respectively; $\mathrm{p}=0.028$ ) (Figure 3 ).

\section{DISCUSSION}

This study demonstrated that there was no superiority among SES, BES, and CS for AIB lesions treated by KS treatment, regarding the risk factors for development of ISR and primary patency rates. Younger age and longer aortic stent segment were significant determinants of ISR. The $82 \%, 88 \%$, and $85 \%$ primary 60 -month patency rates for SES, BES, and CS, respectively are lower than the results of open surgery, ${ }^{[3]}$ but comparable with previous endovascular experiences. ${ }^{[7]}$

Since the 1990s, the treatment of complex aortoiliac lesions, KS treatment has been used, in which abutting or crossed bilateral stents are deployed simultaneously for the reconstruction of the AIB. ${ }^{[11,12]}$ Over the last decade, interventionists pay more interest to $\mathrm{KS}$ treatment, contributing to the literature. The most recent review found early and mid-term patency rates of KS treatment as acceptable treatment options. ${ }^{[13]}$ Moreover, a meta-analysis concluded that, with the improvement of the KS technique, an endovascular first approach might be indicated in case of all AIOD including AIB. ${ }^{[7]}$

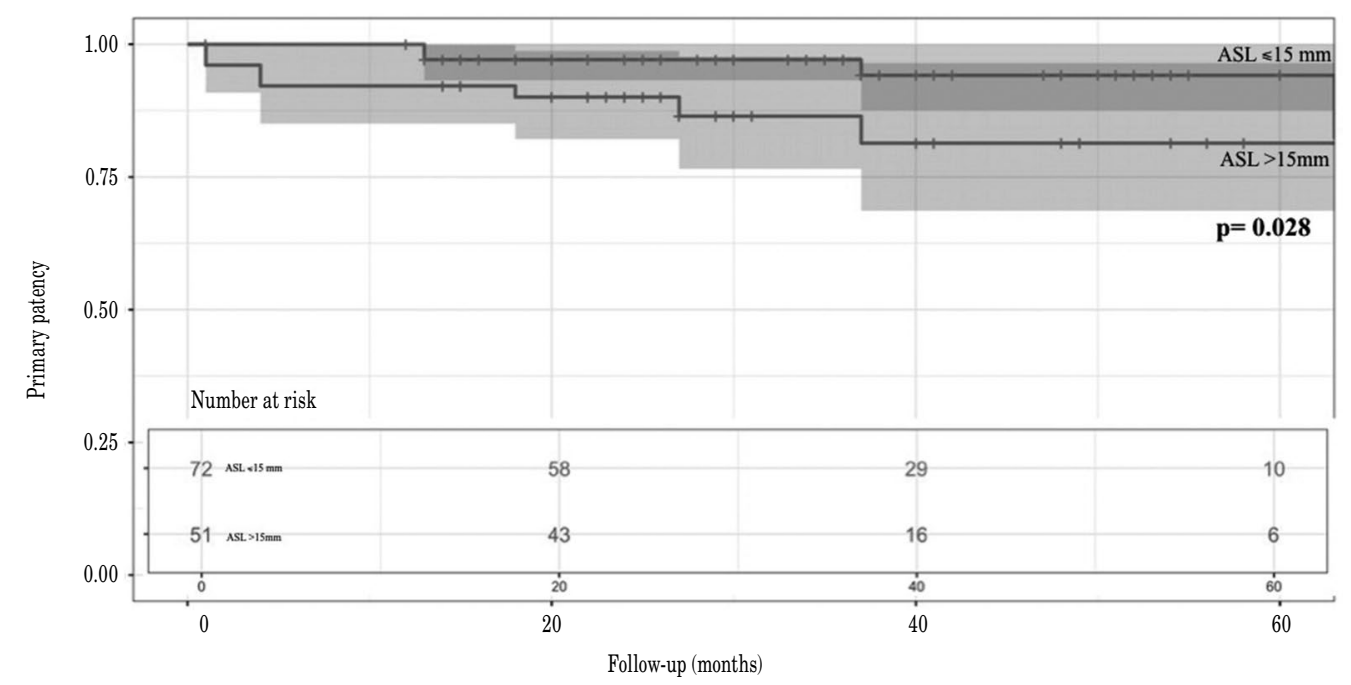

Figure 3. Kaplan-Meier curves of overall primary patency for aortic stent length. 
As previous studies mainly focused on comparing two stent types, this present study is the first to include all three stent types. Sabri et al. ${ }^{[14]}$ reported superior patency of CS to BES at two years of follow-up. $40 \%$ of BES used were 6 or $7 \mathrm{~mm}$ in diameter, and $46.5 \%$ were female patients, indicating a smaller distal aorta, and the sample size was relatively small, which were the main drawbacks of this study. In another study, Aihara et al. ${ }^{[15]}$ focused on AIB lesions and compared SES and BES. Only $26.8 \%$ of the cases were simultaneously deployed KSs and no significant differences were reported in the outcomes based on stent configuration or type. Similarly, a previous study focused on the long-term results and reported no significant difference between the BESs and SESs; however, only $8.6 \%$ of the implanted stents were BESs in this study. ${ }^{[16]}$ In our study, since three stent types were used in a sufficient number of patients, we compared the outcomes and found that stent types did not significantly affect the primary patency rates. This outcome is also consistent with the latest meta-analysis from the current dataset. ${ }^{[7]}$

In the present study, SES was preferred for longer and tortuous lesions, which has been shown to provide perfect early and long-term results in these patients. ${ }^{[17]}$ We used BES for more focal CIA lesions not involving the aorta, to guarantee precise deployment. ${ }^{[18]}$ The CSs were utilized in the reconstruction of aortic bifurcation, which provide a more laminar flow, decreased thrombogenicity, and less chance for prolapse of plaque through the covered stent. ${ }^{[14]}$ Selection of appropriate KS type according to the aforementioned lesion characteristics may have yielded high and comparable patency rates among the stent types. Moreover, compatibility between the stent and vessel diameter to match the specific anatomy of lesions was probably another cause of high patency rates. It was previously demonstrated that the size of mismatch between the stent and vessel wall was predictive for stent patency. ${ }^{[19]}$ Many studies have suggested that the TASC classification influences stent patency, TASC D having the least. ${ }^{[20,21]}$ The TASC lesion did not affect the primary patency rates in our study. As infrarenal occlusions extending AIB (Leriche syndrome) and previous endovascularly or surgically treated patients were excluded from the study, only $20.3 \%$ of the patients had TASC D lesions. Therefore, the patency rates might have been affected from this selection bias.

In the current study, predictors of ISR were also investigated and we found more frequent ISR in younger patients, consistent with previous data. Young patients may have a more intense type of atherosclerosis, becoming more symptomatic and being more prone to progression after treatment and development of patency loss. ${ }^{[22,23]}$ Several studies have also implied the aspects of the KS configuration (poor conformation, stent crossing, radial mismatch) in the development of restenosis. ${ }^{[19,24]}$ Recently, Vértes et al. ${ }^{[25]}$ showed the $>20-\mathrm{mm}$ stent protrusion into aorta as a significant determinant of $\mathrm{KS}$ restenosis. In the present study, an aortic stent length of $>15 \mathrm{~mm}$ was significantly associated with ISR. The reason for the difference might be the 14-mm mean stent length into the aorta in our study, while it was $20.5 \mathrm{~mm}$ in the aforementioned study with $21.9 \%$ ISR, which is $11.3 \%$ higher than our study. As a result, the longer contact of the stents both with the aortic wall and with each other may increase the flow separation and vessel wall shear stress on larger aortic surface areas. Therefore, the risk of thrombus and neointima formation increases and, consequently, the likelihood for development of restenosis increases.

Nonetheless, there are several limitations to our study. First, this is a retrospective, non-randomized research with a long-term follow-up; however, the small number of patients may have affected the power of statistical analysis, particularly for comparisons of subgroups. The choice between a SES, BES, or CS was left to the treating operator's discretion. Second, the type of stent used is influenced by anatomical factors such as severity and length of the lesion, and quality of the stent, thus resulting inherent biases. Third, to obtain a more homogeneous cohort, we excluded patients who had previous endovascular and/or surgical procedures. Meanwhile, it was not possible to perform adjustments equally due to the ISR number. There is a probability of underestimating restenosis, as peripheral angiography was performed, when the patient had recurrent claudication and both DUS and CTA displayed ISR. The ABI and DUS were the principal tools used for follow-up, which may have introduced bias, as they are highly operator-dependent.

In conclusion, the reconstruction of AIB lesions by KS treatment can be performed using SES, BES, or CS with favorable and compatible long-term patency rates. Young age and aortic stent length are independent factors influencing ISR. Further large-scale, prospective, randomized-controlled studies are needed to confirm these findings. 


\section{Declaration of conflicting interests}

The authors declared no conflicts of interest with respect to the authorship and/or publication of this article.

\section{Funding}

The authors received no financial support for the research and/or authorship of this article.

\section{REFERENCES}

1. Chiu KW, Davies RS, Nightingale PG, Bradbury AW, Adam DJ. Review of direct anatomical open surgical management of atherosclerotic aorto-iliac occlusive disease. Eur J Vasc Endovasc Surg 2010;39:460-71.

2. Erdoğan MB, Özçalışkan Ö, Meşe B, Bozoğlan O, İşüuen D, Duran E, et al. Aortoiliak oklüzyonu olan yüksek riskli hastalarda alternatif cerrahi yaklaşım: Lokal anestezi ile aksillofemoral bypass. Damar Cer Derg 2015;24:105-9.

3. de Vries SO, Hunink MG. Results of aortic bifurcation grafts for aortoiliac occlusive disease: A meta-analysis. J Vasc Surg 1997;26:558-69.

4. Rahman A, Özgüler İM. Aortailiyak hastalıklarda cerrahi deneyimlerimiz. Damar Cer Derg 2008;17:61-7.

5. Sevil FC, Tort M. Management of endovascular treatment in spontaneous iliac artery dissections: Applications enabling classical surgery. Turk Gogus Kalp Dama 2020;28:601-8.

6. Olin JW, White CJ, Armstrong EJ, Kadian-Dodov D, Hiatt WR. Peripheral artery disease: Evolving role of exercise, medical therapy, and endovascular options. J Am Coll Cardiol 2016;67:1338-57.

7. Groot Jebbink E, Holewijn S, Versluis M, Grimme F, Hinnen JW, Sixt S, et al. Meta-analysis of individual patient data after kissing stent treatment for aortoiliac occlusive disease. J Endovasc Ther 2019;26:31-40.

8. Indes JE, Pfaff MJ, Farrokhyar F, Brown H, Hashim $\mathrm{P}$, Cheung $\mathrm{K}$, et al. Clinical outcomes of 5358 patients undergoing direct open bypass or endovascular treatment for aortoiliac occlusive disease: A systematic review and meta-analysis. J Endovasc Ther 2013;20:443-55.

9. Norgren L, Hiatt WR, Dormandy JA, Nehler MR, Harris KA, Fowkes FG; TASC II Working Group. InterSociety Consensus for the Management of Peripheral Arterial Disease (TASC II). J Vasc Surg 2007;45 Suppl S:S5-67.

10. Rutherford RB, Baker JD, Ernst C, Johnston KW, Porter JM, Ahn S, et al. Recommended standards for reports dealing with lower extremity ischemia: Revised version. J Vasc Surg 1997;26:517-38.

11. Cheng SW, Ting AC, Ho P, Poon JT. Aortic aneurysm morphology in Asians: Features affecting stent-graft application and design. J Endovasc Ther 2004;11:605-12.

12. Palmaz JC, Encarnacion CE, Garcia OJ, Schatz RA, Rivera FJ, Laborde JC, et al. Aortic bifurcation stenosis: Treatment with intravascular stents. J Vasc Interv Radiol 1991;2:319-23.

13. Groot Jebbink E, Holewijn S, Slump CH, Lardenoije JW, Reijnen MMPJ. Systematic review of results of kissing stents in the treatment of aortoiliac occlusive disease. Ann Vasc Surg 2017;42:328-36.

14. Sabri SS, Choudhri A, Orgera G, Arslan B, Turba UC, Harthun NL, et al. Outcomes of covered kissing stent placement compared with bare metal stent placement in the treatment of atherosclerotic occlusive disease at the aortic bifurcation. J Vasc Interv Radiol 2010;21:995-1003.

15. Aihara H, Soga Y, Iida O, Suzuki K, Tazaki J, Shintani $\mathrm{Y}$, et al. Long-term outcomes of endovascular therapy for aortoiliac bifurcation lesions in the real-AI registry. J Endovasc Ther 2014;21:25-33.

16. Hinnen JW, Konickx MA, Meerwaldt R, Kolkert JL, van der Palen J, Huisman $\mathrm{AB}$, et al. Long term results of kissing stents in the aortic bifurcation. Acta Chir Belg 2015;115:191-7.

17. Houston JG, Bhat R, Ross R, Stonebridge PA. Long-term results after placement of aortic bifurcation self-expanding stents: 10 year mortality, stent restenosis, and distal disease progression. Cardiovasc Intervent Radiol 2007;30:42-7.

18. Leville CD, Kashyap VS, Clair DG, Bena JF, Lyden SP, Greenberg RK, et al. Endovascular management of iliac artery occlusions: Extending treatment to TransAtlantic Inter-Society Consensus class C and D patients. J Vasc Surg 2006;43:32-9.

19. Sharafuddin MJ, Hoballah JJ, Kresowik TF, Sharp WJ, Golzarian J, Sun S, et al. Long-term outcome following stent reconstruction of the aortic bifurcation and the role of geometric determinants. Ann Vasc Surg 2008;22:346-57.

20. de Donato G, Bosiers M, Setacci F, Deloose K, Galzerano G, Verbist J, et al. 24-month data from the BRAVISSIMO: A large-scale prospective registry on iliac stenting for TASC A \& B and TASC C \& D lesions. Ann Vasc Surg 2015;29:738-50.

21. Mwipatayi BP, Sharma S, Daneshmand A, Thomas SD, Vijayan V, Altaf $\mathrm{N}$, et al. Durability of the balloonexpandable covered versus bare-metal stents in the Covered versus Balloon Expandable Stent Trial (COBEST) for the treatment of aortoiliac occlusive disease. J Vasc Surg 2016;64:83-94.e1.

22. Yilmaz S, Sindel T, Golbasi I, Turkay C, Mete A, Lüleci E. Aortoiliac kissing stents: Long-term results and analysis of risk factors affecting patency. J Endovasc Ther 2006;13:291-301.

23. Bérard AM, Bedel A, Le Trequesser R, Freyburger G, Nurden A, Colomer S, et al. Novel risk factors for premature peripheral arterial occlusive disease in non-diabetic patients: A case-control study. PLoS One 2013;8:e37882.

24. Groot Jebbink E, Grimme FA, Goverde PC, van Oostayen JA, Slump CH, Reijnen MM. Geometrical consequences of kissing stents and the covered endovascular reconstruction of the aortic bifurcation configuration in an in vitro model for endovascular reconstruction of aortic bifurcation. J Vasc Surg 2015;61:1306-11.

25. Vértes M, Juhász IZ, Nguyen TD, Veres DS, Hüttl $A$, Nemes B, et al. Stent protrusion $>20 \mathrm{~mm}$ into the aorta: A new predictor for restenosis after kissing stent reconstruction of the aortoiliac bifurcation. J Endovasc Ther 2018;25:632-9. 